\title{
Orbitonasal metallic foreign body
}

\author{
Saumya Yadav, Amar Pujari, Mandeep S Bajaj, Shashwat Behera
}

Department of Ophthalmology, Dr Rajendra Prasad Centre for Ophthalmic Sciences, All India Institute of Medical Sciences, New Delhi, India

\section{Correspondence to}

Dr Amar Pujari,

dramarpujari@gmail.com

Accepted 3 November 2017

\section{DESCRIPTION}

A 23-year-old male patient presented with the history of metallic wire injury following a burst of an instrument. The duration of injury was 2 hours. Clinical examination revealed a visual acuity of 20/20 in each eye, right brow showed a superficial skin laceration. Medial side of the right orbit had an impacted curved metallic wire. Extraocular motility in the right eye was within normal limits (figure 1). Anterior segment and posterior segment examination was unremarkable in both the eyes. B-scan ultrasound revealed a high amplitude spike along the side of the right globe but without any penetration; however, it showed curvilinear course along the medial orbital wall (figure 2A).

To delineate further the actual course of the foreign body, an immediate non-contrast CT was performed. Along the axial sections, the metallic foreign body was curved taking a direction towards the medial orbital wall and thus penetrating it (figure 2B,C). The patient did not have any history of nasal bleeding or loss of consciousness and also nasal cavity examination by an otorhinolaryngologist did not reveal any intranasal findings except for congestion. Under local anaesthesia, after taking all aseptic precautions the metallic foreign body was removed with firm anterior traction (figure 2D). Postoperative care included broad-spectrum oral antibiotics for a week in conjunction with the analgesic. At the end of 1 week (figure 3 ) and 3 months, the patient had an uneventful clinical course with well-preserved extraocular motility and visual acuity.
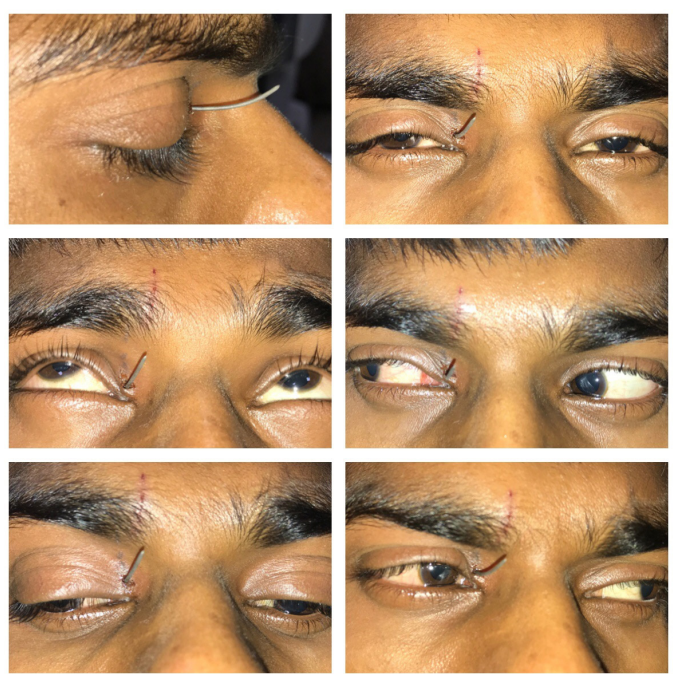

To cite: Yadav S, Pujari A, Bajaj MS, et al. BMJ Case Rep Published Online First: [please include Day Month Year]. doi:10.1136/bcr-2017223253

Figure 1 Front and lateral clinical profile showing a curvilinear metallic foreign body impacted along the superior and nasal aspect of the right upper eyelid.
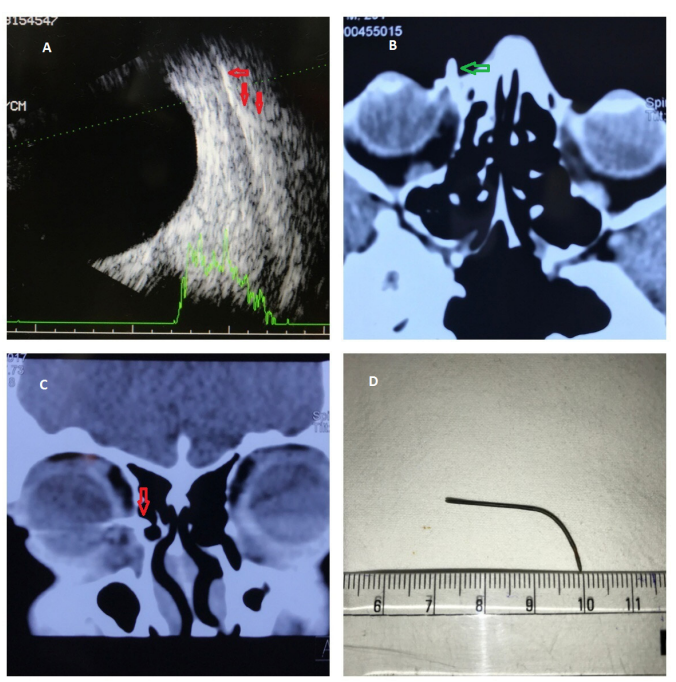

Figure 2 (A) B-scan ultrasound on lateral longitudinal view showing a continuous high spike corresponding to the path travelled by the foreign body with medial deflection. (B and C) Axial sections of non-contrast CT showing the foreign body impaction of the medial wall (green arrow), whereas the coronal section revealed a breach in the medial orbital wall with sinus entry (red arrow). (D) The foreign body after removal.

Orbital foreign bodies can be of various types; whenever the visual benefits overweigh the clinical difficulties, intervention for orbital foreign body removal is better considered. The common complications include associated globe and optic nerve injury leading visual compromise; other important complications include chronic orbital inflammation and infection, osteomyelitis, proptosis, orbital abscess and orbital haematoma. ${ }^{12}$ Secondary infections are common due to Staphylococcus, Bacillus cereus, polymicrobial and other fungal elements. Thorough clinical evaluation followed by appropriate clinical imaging is necessary before intervention in all cases. Ultrasound is usually not the preferred modality for orbital foreign body as compared with intraocular foreign bodies. Here,

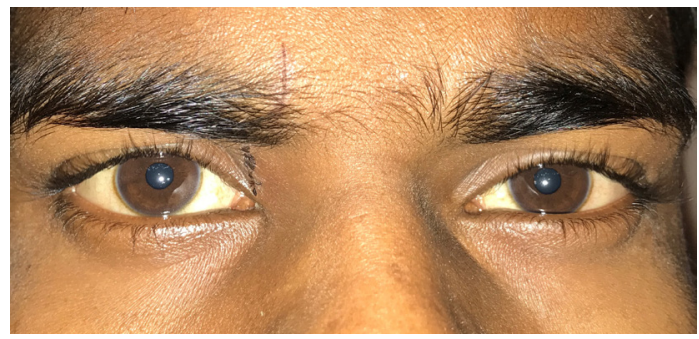
Extraocular motilities were unaffected.
Figure 3 At the end of 1 week, there was no residual abnormality. 
in the current case, the course of the foreign body was unpredictable on clinical examination but a careful ultrasound evaluation revealed the suspicious unusual course towards the medial orbital wall to gain access into either nasal cavity or into the cranium.

Initial orbital plain radiograph followed by non-contrast CT is the preferred protocol for the screening and defining the course of the metallic foreign body in and around the orbit. ${ }^{12}$ Early clinical intervention for superficial foreign body with preliminary

\section{Learning points}

- Orbital metallic foreign bodies in majority of instances have a clinically unpredictable course within the orbit in cases of high-velocity injuries.

- Skilful clinical evaluation followed by thorough imaging helps in identifying the actual path of foreign body to achieve optimal visual and cosmetic results. clinical and plain radiographic findings may be optimal but for deeper foreign body which is breaching the orbital boundaries to enter into the adjacent nasal and cranial cavity need combined detailed clinical and imaging findings for optimal visual and cosmetic outcomes.

Contributors All authors have evaluated the case thoroughly and managed optimally for a better outcome. After evaluating the educational value of the case, all authors wrote the report together.

Competing interests None declared.

Patient consent Obtained.

Provenance and peer review Not commissioned; externally peer reviewed.

(c) BMJ Publishing Group Ltd (unless otherwise stated in the text of the article) 2017. All rights reserved. No commercial use is permitted unless otherwise expressly granted.

\section{REFERENCES}

1 Simha A, John M, Albert RR, et al. Orbito-sinal foreign body. Indian J Ophthalmol 2010;58:530.

2 Asif JA, Pohchi A, Alam MK, et al. An intraorbital metallic foreign body. Indian J Ophthalmol 2014;62:1098.

Copyright 2017 BMJ Publishing Group. All rights reserved. For permission to reuse any of this content visit

http://group.bmj.com/group/rights-licensing/permissions.

BMJ Case Report Fellows may re-use this article for personal use and teaching without any further permission.

Become a Fellow of BMJ Case Reports today and you can:

- Submit as many cases as you like

- Enjoy fast sympathetic peer review and rapid publication of accepted articles

- Access all the published articles

Re-use any of the published material for personal use and teaching without further permission

For information on Institutional Fellowships contact consortiasales@bmjgroup.com

Visit casereports.bmj.com for more articles like this and to become a Fellow 